\title{
Viability of Polysulfide-Retaining Barriers in Li-S Battery
}

\author{
Erik J. Berg $\oplus^{*}$ and Sigita Trabesinger $\oplus^{*, z}$ \\ Electrochemistry Laboratory, Paul Scherrer Institute, CH-5232 Villigen PSI, Switzerland
}

\begin{abstract}
Lithium-sulfur (Li-S) batteries are among the most promising candidates for future high-energy, low-cost energy-storage systems. However, still many challenges have to be solved on the way to their commercialization. One of the most prominent of those is related to the polysulfide shuttle. In recent years, various approaches have been developed to contain, control or eliminate its effects, and thus to achieve higher specific charge, higher coulombic efficiencies and longer cycling life. One of recurring approaches is best described as introducing 'polysulfide barriers', either inorganic or polymeric membranes with lithium-ion conduction or interlayers with adsorptive properties, preventing polysulfides from reaching the lithium metallic anode. All of these approaches result in improved performance and longer cycling life of the Li-S battery. However, little attention has been given to the commercial viability of such solutions. Here we present a simple model to evaluate the practicability of polysulfide barriers in terms of gravimetric and volumetric energy densities as well as cost. We take into account the effects of barrier thickness, the physical properties and cost of the materials they are made of, as well as account for sulfur loading when assessing the viability of polysulfide barrier implementation into a practical $\mathrm{Li}-\mathrm{S}$ cell.

(C) The Author(s) 2017. Published by ECS. This is an open access article distributed under the terms of the Creative Commons Attribution Non-Commercial No Derivatives 4.0 License (CC BY-NC-ND, http://creativecommons.org/licenses/by-nc-nd/4.0/), which permits non-commercial reuse, distribution, and reproduction in any medium, provided the original work is not changed in any way and is properly cited. For permission for commercial reuse, please email: oa@electrochem.org. [DOI: 10.1149/2.0021801jes] All rights reserved.

(cc) BY-NC-ND
\end{abstract}

Manuscript submitted August 29, 2017; revised manuscript received September 18, 2017. Published September 30, 2017. This paper is part of the JES Focus Issue on Lithium-Sulfur Batteries: Materials, Mechanisms, Modeling, and Applications.

The Li-S battery combines several attractive properties, most importantly a high theoretical energy density, high theoretical specific charge and low cost. ${ }^{1-5}$ Moreover, the abundance of elemental sulfur — the active material in the Li-S battery — makes commercialization of this system even more desirable. The main drawback of sulfur as the active material is its insulating nature, which also applies to the $\mathrm{Li}_{2} \mathrm{~S}$, an end product of the lithiation reaction upon discharge. ${ }^{5,6} \mathrm{How}-$ ever, the most detrimental process within $\mathrm{Li}-\mathrm{S}$ cells is the polysulfide shuttle, which is triggered when highly soluble long-chain polysulfides are formed upon sulfur lithiation. Due to their high mobility in electrolyte, they can leach out from the positive electrode and reside in the electrolyte. There, polysulfides disproportionate in contact with other polysulfides or sulfur, and are partially oxidized or reduced when interacting with the positive or negative electrode, respectively. This leads to 'endless' red-ox shuttle, often referred to as the 'polysulfide shuttle'. ${ }^{4,7}$ In addition, a part of the dissolved polysulfides can also be fully reduced at the negative electrode, forming an insulating layer; as a result, part of the active material is irreversibly lost and at the same time the resistance of the negative electrode is increased. The polysulfide shuttle therefore lowers the efficiency of the cell, reduces its specific charge and compromises its lifetime. ${ }^{8-12}$

In recent years, numerous solutions have been proposed to reduce the effects of polysulfide shuttle and to control it. These approaches include encapsulation by or addition of adsorbing inorganic materials, polymers and their composites, electrode coating and adsorptive additives to the electrode, physical barriers in the form of membranes and interlayers. ${ }^{13-22}$ Physical barriers are the simplest and most versatile, as they can be tailored separately from the positive electrode or other parts of the cell. The solid Li-ion conducting membranes can be inorganic or polymeric, or a hybrid of both. However, many traditional solid-polymer electrolytes (SPE) are still permeable to polysulfides, ${ }^{21}$ whereas solid-state inorganic electrolytes (SSIE) ${ }^{23,24}$ can fully retain polysulfides in the positive electrode compartment. The approach using carbon or hybrid interlayers, ${ }^{1,4}$ similar to polymeric membranes, does not completely block but significantly reduces polysulfide access to the negative electrode. All of these avenues have been proven to greatly improve the performance of $\mathrm{Li}-\mathrm{S}$ batteries with respect to specific charge, coulombic efficiency and lifetime.
However, even if specific charge, coulombic efficiency and lifetime are undoubtedly important, when evaluating batteries from a practical point of view, then the judgement is made based on their gravimetric and volumetric energy densities and on their cost. As we have shown in our energy-cost model, superiority ranking of different battery chemistries cannot be directly derived from their theoretical voltage and specific charge values. ${ }^{25} \mathrm{~A}$ fair comparison requires accounting for all cell components contributing to the weight, volume and cost - beyond the active materials alone. As for each battery chemistry (depending on the properties of active materials) different amounts of conductive additives, binders and electrolyte are required, the overall values of achievable energy densities as well as cost of a cell with a given chemistry will be different. Similarly, the balance between negative and positive electrodes will influence these values, as they depend on pairing of active materials in the cells.

With this study we aim to assess the viability of different polysulfide-barrier approaches for controlling the polysulfide shuttle. More specifically, we analyzed gravimetric and volumetric energy densities and the cost depending on the properties of solid-state membranes and carbon-based interlayers, to understand their limitations while keeping in mind their versatility and reported significant improvements in $\mathrm{Li}-\mathrm{S}$ battery performance.

\section{Model and Assumptions}

This study is based on our energy-cost model, ${ }^{25}$ which has been developed by distilling key features of more detailed works ${ }^{26-28}$ to enable simplyfied comparison and evaluation of different battery chemistries. This model is now expanded to be suitable for evaluating the effects of polysulfide barriers on gravimetric and volumetric energy densities and the cost of $\mathrm{Li}-\mathrm{S}$ cells. The two types of barriers evaluated are solid-state inorganic Li-conductive membranes, similarly as those in work of McCloskey, ${ }^{29}$ and carbon-based interlayers, which have not been assessed previously. Similarly as in the energy-cost model, cycling stability and lifetime are not factored in; only physical properties of the raw materials and their cost are taken into consideration, see Tables I and II. As before, a prismatic pouch cell of a typical industrial design (illustrated in Figure 1) is taken as the basis for our calculation, giving rise to several limitations, ${ }^{25}$ whereas processing costs are neglected in the present study. More specifically: 
Table I. Cell active and inactive material properties and cost.

\begin{tabular}{|c|c|c|c|c|c|}
\hline Material & Abbreviation & $\begin{array}{l}\text { Practical average discharge } \\
\text { potential }\left(\mathrm{V} \mathrm{vs} \mathrm{Li}^{+} / \mathrm{Li}\right)\end{array}$ & $\begin{array}{l}\text { Practical specific } \\
\text { charge }\left(\mathrm{mAh} \mathrm{g}^{-1}\right)\end{array}$ & Density $\left(\mathrm{g} \mathrm{cm}^{-3}\right)$ & Cost $\left(\$ \mathrm{~kg}^{-1}\right)$ \\
\hline $\mathrm{LiNi}_{\mathrm{x}} \mathrm{Mn}_{\mathrm{y}} \mathrm{Co}_{\mathrm{z}} \mathrm{O}_{2}$ & NMC & 3.7 & 180 & 4.75 & 33 \\
\hline Lithium sulfide & $\mathrm{Li}_{2} \mathrm{~S}$ & 2.1 & 1000 & 1.66 & 0.05 \\
\hline Graphite $\left(\mathrm{LiC}_{6}\right)$ & $\mathrm{Gr}$ & 0.1 & 370 & 2.2 & 19 \\
\hline Lithium & $\mathrm{Li}$ & 0 & 3884 & 0.53 & 100 \\
\hline Electrolyte & ELY & - & - & 1.2 & 18 \\
\hline Current collector (7-) & $\mathrm{Cu}$ & - & - & 8.96 & 25 \\
\hline Current collector $(+)$ & $\mathrm{Al}$ & - & - & 2.7 & 15 \\
\hline
\end{tabular}

Table II. Barrier-material properties and estimated cost.

\begin{tabular}{cccccc} 
Barrier & Abbreviation & Porosity & Density $\left(\mathrm{g} \mathrm{cm}^{-3}\right)$ & $\mathrm{Cost}_{\left(\$ \mathrm{~kg}^{-1}\right)}$ & $\left.\mathrm{Cost}_{(\$ \mathrm{~m}}{ }^{-2}\right)$ \\
\hline Separator (Celgard) & - & 0.3 & 0.95 & 120 & 1.98 \\
Solid-state inorganic membrane & SSIM & 0 & 3.05 & 157 & - \\
Carbon-based interlayer & C-interL & 0.6 & 2.2 & 2.2 & $\sim 20$ \\
Conductive carbon & C-interL & 0.6 & 2.2 & $\sim 100$ & $\sim 0.5$ \\
Carbon nanotubes & C-interL & 0.6 & 2.2 & $\sim 950$
\end{tabular}

1) Electrode compositions are defined depending on active-material properties: $60 \mathrm{wt} \%$ active non-lithiated material, $30 \mathrm{wt} \%$ conductive carbon additive, and $10 \mathrm{wt} \%$ binder for sulfur cells unless otherwise specified, and $93 \mathrm{wt} \%$ of active material, $4 \mathrm{wt} \%$ of conductive carbon additive and $3 \mathrm{wt} \%$ of binder for NMC cells. Sulfur loadings in the range of $0.5 \mathrm{mg} \mathrm{S} / \mathrm{cm}^{2}$ to $6 \mathrm{mg} \mathrm{S} / \mathrm{cm}^{2}$ were modelled by varying the weight ratio of sulfur to Carbon-Binder $\left(\mathrm{mg}_{\mathrm{S}} / \mathrm{mg}_{\mathrm{C}+\text { binder }}\right)$, while keeping the carbon to binder weight-ratio constant.

2) The electrode porosity is constant and assumed to be $30 \%$ in the discharged state of the positive electrodes, as is suitable for a cell optimized for high-energy density: The porosity is a tradeoff between energy and power density since a higher porosity reduces the active material amount and a lower porosity would significantly hamper ion transport. Volume expansion of the positive electrodes is not accounted for, as the calculations are made based on discharged (expanded) state.

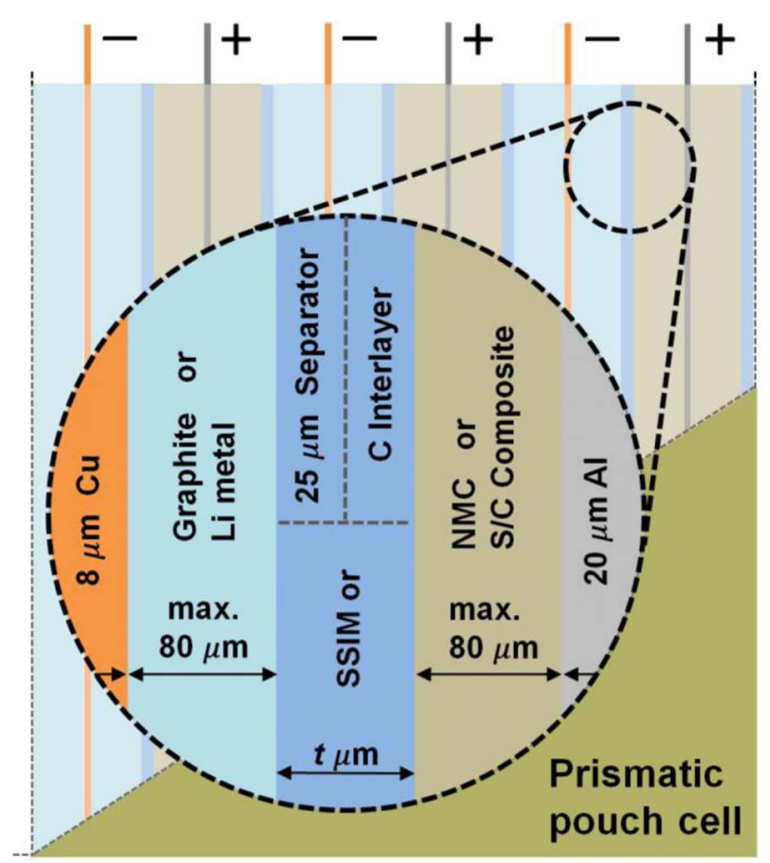

Figure 1. Simplified schematic of prismatic pouch-cell components assumed in the model (Adapted from Berg et al. ${ }^{25}$ ).
3) The thickness of the electrodes is limited to $80 \mu \mathrm{m}$; e.g., the thickness of the electrode with lower energy density is set to $80 \mu \mathrm{m}$ and that of the counter electrode is adjusted to chargebalanced loading and, correspondingly, thickness.

4) Electrode materials are assumed to be double-side coated on current collectors of $8-\mu \mathrm{m} \mathrm{Cu}$ and $20-\mu \mathrm{m} \mathrm{Al}$.

5) $50 \% \mathrm{Li}$ excess in the Li metal anode is assumed.

For the evaluation of the viability of polysulfide barriers, Ohara glass (LICGC, Ohara Corporation) was chosen as a representative of solid-state inorganic membranes, whereas various carbon materials were considered for carbon-based interlayers, see Table II. For the solid-state inorganic membrane, the porosity was assumed to be zero, whereas for carbon-based interlayers we assumed it to be rather high, $60 \%$. For all calculations concerning carbon-based interlayers we assumed the presence of a Celgard separator, because carbon interlayers are electronically conductive and they require an insulator layer for the cell to work. All properties, including thickness, density, porosity and cost, are accounted for assuming a standard Celgard separator with properties shown in Table II.

No prices are available for carbon interlayers, and the cost estimation is therefore rather crude. The prices used in this study are based on estimated costs for raw carbon material. We started with specialty conductive high-surface-area carbons, and took a price range up to the possible cost of graphene, which we on purpose lowered from its current market price. For assessing the competiveness of the cells with polysulfide barriers, they are presented in comparison with the following electrochemical couples: $\mathrm{Li}_{2} \mathrm{~S}-\mathrm{Li}, \mathrm{NMC}-\mathrm{Li}, \mathrm{NMC}-$ Graphite with standard separators and NMC-Li with solid-state inorganic membrane.

Again, as in our previous work, our calculations are not intended to provide precise costs of the final battery cell, but instead to encourage researchers in the field to compare different solutions offered for addressing the challenges associated with the commercialization of Li-S batteries, to assess their practicability and their effects on gravimetric and volumetric energy densities and on overall cell cost.

\section{Barrier-Thickness Effect}

One of the limiting parameters for the viability of polysulfide barriers is their thickness, as it greatly affects gravimetric and volumetric energy densities as well as cost. The thickness is very important also with a view to practical implementations - the thicker the barrier, the easier it is to handle.

Figure 2 shows how gravimetric and volumetric energy densities would be affected by the thickness of the polysulfide barrier and how it 

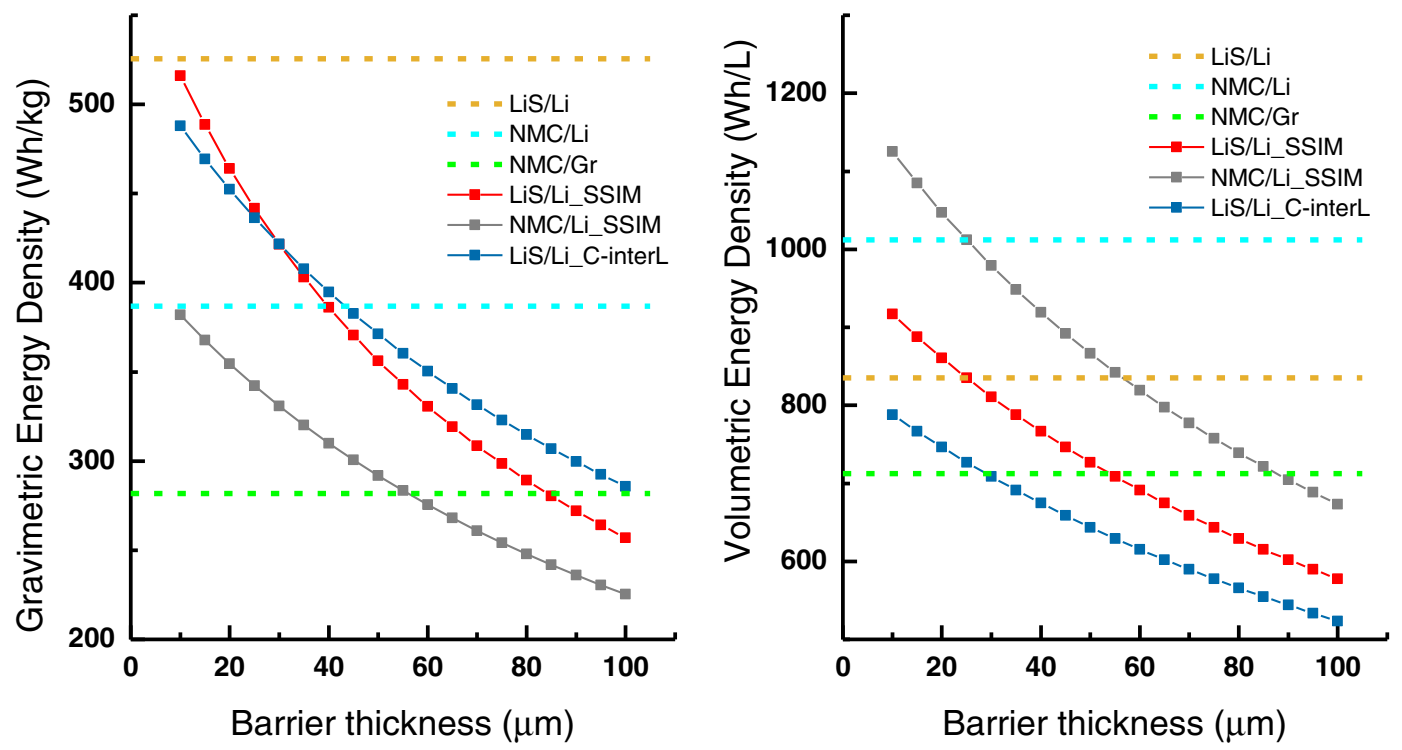

Figure 2. Gravimetric (left) and volumetric (right) energy densities as a function of polysulfide-barrier thickness (sulfur loading $4 \mathrm{mg} \mathrm{cm}^{-2}$ ).

compares not only to the standard Li-S battery (in yellow) and Li-ion battery based on NMC-Graphite (in green) but also to NMC-Li and the same with SSIM (in cyan and grey, respectively). Sulfur loading in $\mathrm{Li}-\mathrm{S}$ cells is assumed to be at an intermediate level of $4 \mathrm{mg} \mathrm{cm}^{-2}$ and NMC loading is set to $22.6 \mathrm{mg} \mathrm{cm}{ }^{-2}$ (or $3.85 \mathrm{mAh} / \mathrm{cm}^{2}$ ) as customary for a high-energy Li-ion cell. ${ }^{30}$ It is evident from Figure 2 (left) that the NMC-Li cell with SSIM will be inferior at any membrane thickness in terms of gravimetric energy density, compared to any of the $\mathrm{Li}-\mathrm{S}$ cell configurations. Li-S cells with either type of barrier - solid-state inorganic membrane or carbon based interlayer - always would have lower gravimetric energy density than one with the standard separator only (for properties see Table II) as the density of SSIM is much higher and because the $\mathrm{C}$-interL $\mathrm{Li}-\mathrm{S}$ cell contains not only the interlayer but also the standard separator. For SSIM to compete with standard Li-ion cells (NMC/Gr), its thickness has to be less than $80 \mu \mathrm{m}$. To compare favorably relative to $\mathrm{NMC} / \mathrm{Li}$ cell, the SSIM should be less than $40 \mu \mathrm{m}$ in thickness, and even thinner $(\sim 35 \mu \mathrm{m})$ to compete with carbon interlayers in terms of gravimetric energy density. At the same time, the cell containing $\mathrm{C}$-interL is competitive relative to the standard Li-ion cell configuration once the interlayer is made thinner than $100 \mu \mathrm{m}$. For a barrier thickness of $\sim 30 \mu \mathrm{m}$, both SSIM and C-interL would lead to the same gravimetric energy density of the Li-S cell, wherefrom SSIM would be superior for lower thicknesses whilst C-interL would be superior to SSIM for thicknesses higher than $30 \mu \mathrm{m}$. All this lead to the conclusion that when competing in gravimetric energy density with $\mathrm{Li}$-ion cells, the polysulfide barriers in $\mathrm{Li}-\mathrm{S}$ cells should have thickness not exceeding $80 \mu \mathrm{m}$, and if metallic anodes are realized for traditional Li-ion cathodes, then they would be competitive only starting at thicknesses of $25 \mu \mathrm{m}$ (same as the Celgard-separator thickness) and below. However, it is very challenging to produce such thin SSIMs, and processing cost might be so high that they would be prohibiting commercialization of such cells.

When evaluating the dependence of the volumetric energy density on polysulfide-barrier thickness (Figure 2, right), the relationship is simpler than in case of gravimetric energy density. The highest achievable volumetric energy density is reached by NMC-Li with SSIM, if the SSIM can be made thinner than $25 \mu \mathrm{m}$ (the thickness of a standard separator). The volumetric energy density of NMC-Li with SSIM will also be always higher than that of $\mathrm{Li}-\mathrm{S}$ cells with either type of barrier - SSIM or C-interL - and at any polysulfide-barrier thickness studied here, due to the active-material density and low conductivecarbon content in the cathode. When comparing SSIM and C-interL to one another, SSIM is superior regarding volumetric energy density, due to the low porosity and high density of SSIM. The thickness of these two barriers has to be below $50 \mu \mathrm{m}$ for SSIM and below 25 $\mu \mathrm{m}$ for $\mathrm{C}$-interL, respectively, to compete in volumetric energy density even with $\mathrm{NMC/Gr}$ cells. C-interL cannot rival any other setup, independently of how thin it would be made, whereas, in a manner similar as for NMC cells, the Li-S cell with SSIM can exceed the volumetric energy density $\mathrm{Li}-\mathrm{S}$ cell containing of standard separators when the thickness of the SSIM is below that of the standard separator. As expected, the thickness of the polysulfide barrier is more crucial for volumetric energy density than for gravimetric, where it can be compensated by lightness and high porosity.

The thickness of the polysulfide barrier also influences the overall cell costs, see Figure 3. For the Li-S cell with SSIM (red) to compete in cost with the NMC/Gr standard cell (green), the SSIM should be less than $\sim 15 \mu \mathrm{m}$ thick. The competitiveness of $\mathrm{C}$-interL depends critically on the cost of the carbon it is made from. When low-cost

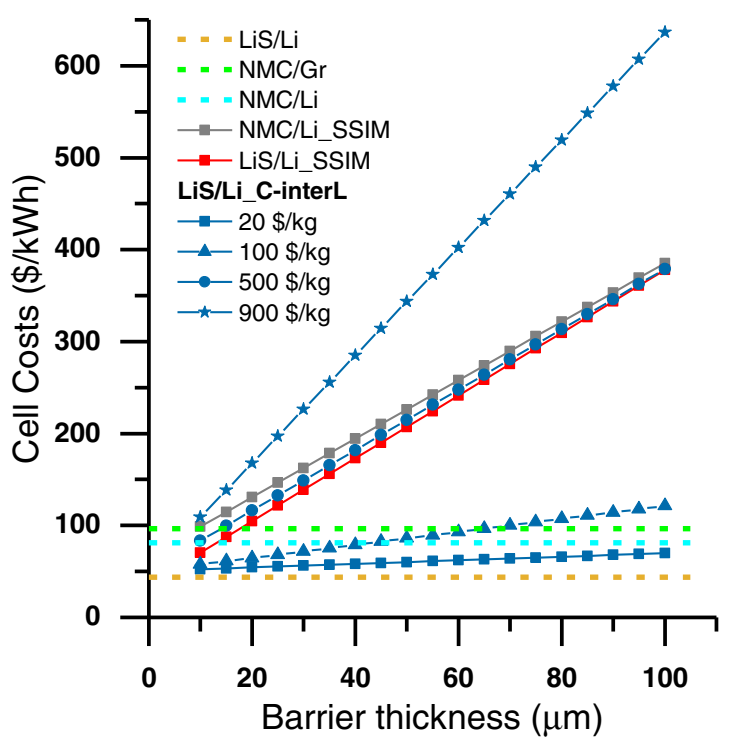

Figure 3. Overall cell cost depending on the thickness of the polysulfide barrier (sulfur loading $4 \mathrm{mg} \mathrm{cm}^{-2}$ ). 


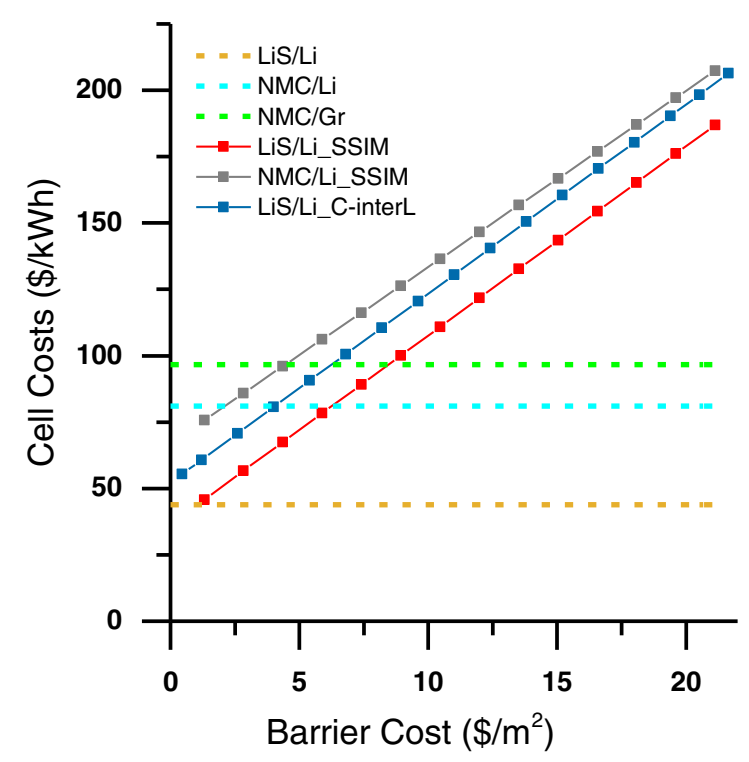

Figure 4. Effect of the barrier cost on the overall cell cost at barrier thickness of $25 \mu \mathrm{m}$ (sulfur loading $4 \mathrm{mg} \mathrm{cm}^{-2}$ ).

carbon (blue squares), such as active carbons, is used, the cell can compete with NMC-based ones (NMC/Gr and NMC /Li) even when the $\mathrm{C}$-interL is thicker than $100 \mu \mathrm{m}$. However, for carbon nanotubes (blue triangles), it must not exceed 40-60 $\mu \mathrm{m}$ to stay competitive, and for even more expensive carbons such as graphene (blue stars), a CinterL will not give any cost advantage to $\mathrm{Li}-\mathrm{S}$ cell at any thickness; it cannot even compete with the $\mathrm{Li}-\mathrm{S}$ cells containing SSIM. The $\mathrm{C}$-interL carbon must be cheaper than $500 \$ \mathrm{~kg}^{-1}$ to be on par with or better than the SSIM-containing Li-S cells. At the same time it is clear from Figure 3 that SSIM-containing Li-S cell have no significant advantage over NMC/Li_SSIM with the same thickness of SSIM. From this graph it is also obvious that $\mathrm{Li}-\mathrm{S}$ cells with $\mathrm{C}$-interL can be competitive in terms of cell cost only if they are made of cheap carbon.

\section{Barrier-Cost Effect}

Naturally, the competitiveness of polysulfide barriers is bound also by the barrier-cost itself. From the results shown in Figure 4 it is clear that any barrier in the $\mathrm{Li}-\mathrm{S}$ cell has to be rather cheap when competing with standard Li-ion (NMC/Gr, green). A competitive price of SSIM is below $8 \$ \mathrm{~m}^{-2}$, whereas the value is even lower for C-interL, below $6 \$ \mathrm{~m}^{-2}$, as for $\mathrm{Li}-\mathrm{S}$ cells with $\mathrm{C}$-interL also the cost of the standard separator has to be added. Therefore, the carbon based interlayer itself has to be cheaper per square meter than the SSIM. Costs higher than $20 \$$ per square meter were not considered, as $20 \$ \mathrm{~m}^{-2}$ already corresponds to $\sim 300 \$ \mathrm{~kg}^{-1}$ for SSIM and $\sim 950 \$ \mathrm{~kg}^{-1}$ for carbon in C-interL.

\section{Sulfur-Loading Effect}

As has been previously shown, ${ }^{29}$ the sulfur loading is a decisive parameter when it comes to energy and cost efficiency of $\mathrm{Li}-\mathrm{S}$ batteries. We have therefore looked at the sulfur loading needed to compete, again, with standard and metallic-lithium-containing NMC cells, for different polysulfide barriers. We found that the $\mathrm{Li}-\mathrm{S}$ cells with sulfur loading below $1.5 \mathrm{mg} \mathrm{cm} \mathrm{cm}^{-2}$ can be directly excluded from competition with Li-ion batteries when considering gravimetric energy density, whereas to compete with NMC-Li cells, the necessary sulfur loading would be even higher - above $2-3 \mathrm{mg} \mathrm{cm}^{-2}$ (Figure 5, left).

In case of volumetric energy density (Figure 5, right), a loading of $2.5 \mathrm{mg} \mathrm{cm}^{-2}$ is required to compete with NMC/Gr cells in case of standard and SSIM-containing Li-S cells, because as long as the membrane thickness is the same as the standard separator (as for example for functionalized standard separators ${ }^{8}$ ), the volumetric energy density is as well the same. In case of C-interL, the loading required to compete with $\mathrm{NMC} / \mathrm{Gr}$ cells is much higher $\left(\sim 4 \mathrm{mg} \mathrm{cm}^{-2}\right)$ as, in addition to the interlayer, a standard separator is needed for the cell to function. Moreover, no realistic sulfur loading will make the $\mathrm{Li}-\mathrm{S}$ cell competitive, with regard to volumetric energy density, relative to NMC in combination with a metallic lithium anode (Figure 5, right). For comparison, the sulfur to electrolyte weight ratio (S/ELY Ratio) is additionally included in Figure 5, but this ratio is linearly dependent on the $\mathrm{S}$ loading under the assumption of a constant porosity of $30 \%$ (e.g. total electrolyte amount remains constant while $\mathrm{S}$ to $\mathrm{C}$ ratio in the electrode changes).
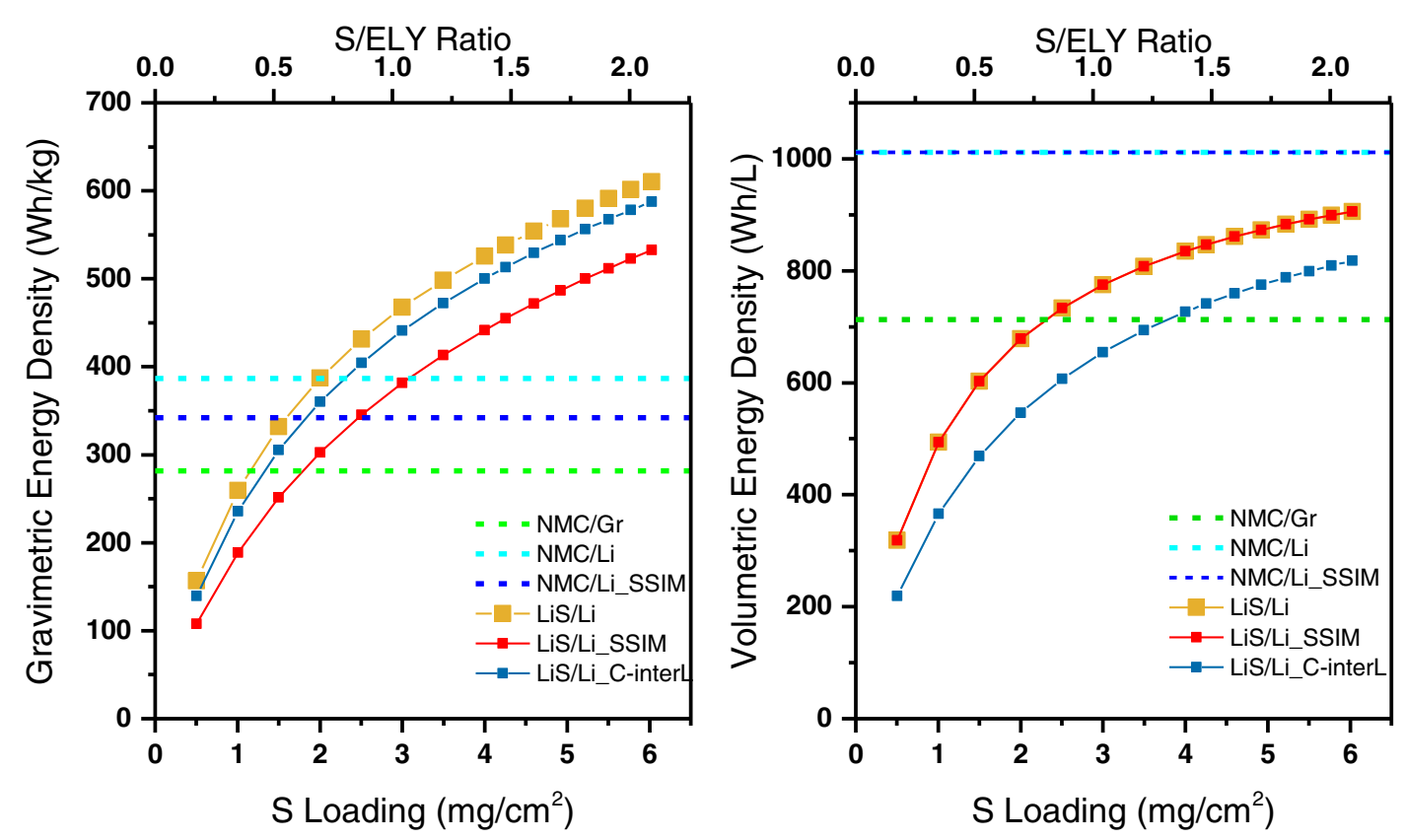

Figure 5. Effect of sulfur loading on gravimetric and volumetric energy densities of cells with various polysulfide barriers (with a fixed thickness of $25 \mu \mathrm{m}$ ). 


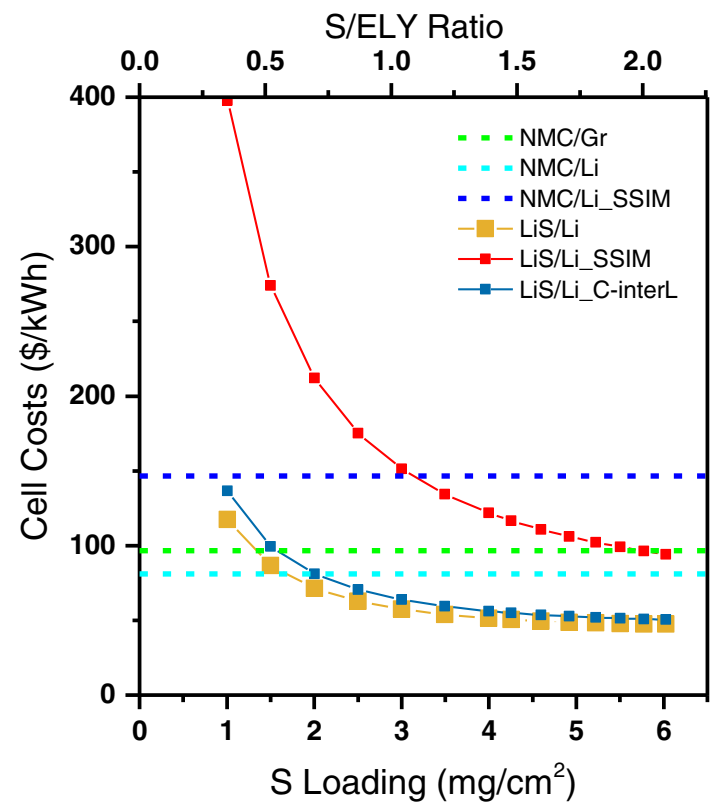

Figure 6. Effect of sulfur loading on the overall cell costs for various polysulfide barriers (thickness $25 \mu \mathrm{m}$ ) and the $\mathrm{C}$-interL made from the cheapest carbon considered $\left(20 \$ \mathrm{~kg}^{-1}\right)$.

When considering the cost development for increasing sulfur loading (Figure 6), a large gap appears between $\mathrm{Li}-\mathrm{S}$ cells with standard separator (yellow) and cells with SSIM. For viable SSIM cells, the extrapolated loading of sulfur must be more than $10 \mathrm{mg} \mathrm{cm}^{-2}$ for it to become cheaper than the Li-ion cell if the thickness of the SSIM is set to $25 \mu \mathrm{m}$. Otherwise, to keep realistic loadings, the SSIM should be much thinner. The cost of the cell with $\mathrm{C}$-interL, if cheap carbon is used, remains close to the cost of $\mathrm{Li}-\mathrm{S}$ cell with standard separator and, in this case, loadings starting from $2.5-3 \mathrm{mg} \mathrm{cm}^{-2}$ would already give a considerable cost advantage over NMC cells.

\section{Conclusions}

The present analysis of polysulfide barriers shows that both solidstate inorganic membranes and carbon-based interlayers, which are both beneficial for increasing the life time and performance of $\mathrm{Li}-\mathrm{S}$ battery cells, have their advantages and disadvantages with regard to practical applications. The common trend is that such polysulfide barriers need to be thin to be competitive relative to Li-ion cells, which, in turn, might heavily compromise their mechanical properties. SSIM has a relatively high density and zero porosity, and is therefore especially affected by the thickness limits, as the main advantageous characteristics of the SSIM-containing cells rely on it being thinner than the standard separator. At the level where the SSIM thickness becomes competitive (that is, below $\sim 20 \mu \mathrm{m}$ ), its production and handling during cell assembly, and later during operation, can pose serious difficulties and would most likely make processing cost dominant in overall cell costs of the cell. With SSIMs of thicknesses below $20 \mu \mathrm{m}, \mathrm{Li}-\mathrm{S}$ cells can achieve higher gravimetric energy densities than with $\mathrm{C}$-interL and higher volumetric energy densities than standard Li-S cells; however, cost-wise its advantage would always be at best minor.

The cells with carbon-containing interlayers will always have lower energy and cost performance than $\mathrm{Li}-\mathrm{S}$ cells with standard separators, due to the need of an insulating layer, given that carbonbased interlayers are conductive. However, in comparison to SSIM, they have clear advantages in terms of gravimetric energy density at higher polysulfide-barrier thicknesses. At the same time, from the evaluation of the costs it is clear that if C-interL is made from a cheap carbon, its cost would be competitive with costs of Li-ion cells over the wide range of polysulfide-barrier thicknesses. Carbon-based interlayers can be a viable option for low-cost batteries if the loss of a part of gravimetric and volumetric energy density is acceptable for the particular application, whereas high-cost carbon-based interlayers do not have any advantages from a practical point of view.

This evaluation can be further expanded to assess the practical viability of other polysulfide barriers: different solid-state membranes, solid inorganic, solid polymeric and hybrid electrolytes, as well as carbon-based interlayers with various dopings, or other hybrid polysulfide barriers, containing not only carbons but also inorganic adsorbents or polysulfide-repulsive coatings. The variety of the research on polysulfide barriers has expanded significantly and our methodology can be used to assess each particular approach for its commercial viability.

\section{Acknowledgments}

Erik J. Berg acknowledges financial support provided by Swiss National Science Foundation (SNSF) under the "Ambizione Energy" funding scheme (Grant No. 160540).

\section{ORCID}

Erik J. Berg (10) https://orcid.org/0000-0001-5653-0383 Sigita Trabesinger (1D https://orcid.org/0000-0001-5878-300X

\section{References}

1. S. Urbonaite, T. Poux, and P. Novák, Advanced Energy Materials, 5, 1500118 (2015)

2. L. F. Nazar, M. Cuisinier, and Q. Pang, MRS Bulletin, 39, 436 (2014)

3. X. Ji and L. F. Nazar, Journal of Materials Chememistry, 20, 9821 (2010).

4. A. Rosenman, E. Markevich, G. Salitra, D. Aurbach, A. Garsuch, and F. F. Chesneau, Advanced Energy Materials, 5, 1500212 (2015).

5. M. A. Pope and I. A. Aksay, Advanced Energy Materials, 5, 1500124 (2015).

6. C. Raiß, K. Peppler, J. Janek, and P. Adelhelm, Carbon, 79, 245 (2014)

7. S. Evers, T. Yim, and L. F. Nazar, The Journal of Physical Chemistry C, 116, 19653 (2012).

8. J. Conder, S. Urbonaite, D. Streich, P. Novak, and L. Gubler, RSC Advances, 5, 79654 (2015).

9. J.-Q. Huang, Q. Zhang, H.-J. Peng, X.-Y. Liu, W.-Z. Qian, and F. Wei, Energy \& Environmental Science, 7, 347 (2014).

10. Y. Diao, K. Xie, S. Xiong, and X. Hong, Journal of Power Sources, 235, 181 (2013).

11. S. S. Zhang, J. Power Sources, 231, 153 (2013).

12. Y. V. Mikhaylik and J. R. Akridge, Journal of The Electrochemical Society, 151, A1969 (2004)

13. S. Evers and L. F. Nazar, Chemical Communications (Cambridge, England), 48, 1233 (2012).

14. Y. J. Choi, B. S. Jung, D. J. Lee, J. H. Jeong, K. W. Kim, H. J. Ahn, K. K. Cho, and H. B. Gu, Physica Scripta, T129, 62 (2007).

15. C. Wang, W. Wan, J.-T. Chen, H.-H. Zhou, X.-X. Zhang, L.-X. Yuan, and Y.-H. Huang, Journal of Materials Chemistry A, 1, 1716 (2013).

16. H. Wang, Y. Yang, Y. Liang, J. T. Robinson, Y. Li, A. Jackson, Y. Cui, and H. Dai, Nano Letters, 11, 2644 (2011).

17. J. W. Choi, J. H. Kim, G. Cheruvally, J. H. Ahn, K. W. Kim, H. J. Ahn, and J. U. Kim, Journal of Industrial and Engineering Chemistry, 12, 939 (2006).

18. G.-C. Li, G.-R. Li, S.-H. Ye, and X.-P. Gao, Advanced Energy Materials, 2, 1238 (2012).

19. K. Park, J. H. Cho, J.-H. Jang, B.-C. Yu, A. T. De La Hoz, K. M. Miller, C. J. Ellison, and J. B. Goodenough, Energy \& Environmental Science, 8, 2389 (2015).

20. S.-H. Chung and A. Manthiram, The Journal of Physical Chemistry Letters, 5, 1978 (2014).

21. S. E. Doris, A. L. Ward, P. D. Frischmann, L. Li, and B. A. Helms, Journal of Materials Chemistry A, 4, 16946 (2016).

22. S.-H. Chung and A. Manthiram, Advanced Materials, 26, 1360 (2014).

23. K. Fu, Y. Gong, G. T. Hitz, D. W. McOwen, Y. Li, S. Xu, Y. Wen, L. Zhang, C. Wang, G. Pastel, J. Dai, B. Liu, H. Xie, Y. Yao, E. D. Wachsman, and L. Hu, Energy \& Environmental Science, 10, 1568 (2017).

24. M. Cuisinier, C. Hart, M. Balasubramanian, A. Garsuch, and L. F. Nazar, Advanced Energy Materials, 5, 1401801 (2015).

25. E. J. Berg, C. Villevieille, D. Streich, S. Trabesinger, and P. Novák, Journal of The Electrochemical Society, 162, A2468 (2015).

26. K. G. Gallagher, S. Goebel, T. Greszler, M. Mathias, W. Oelerich, D. Eroglu, and V. Srinivasan, Energy \& Environmental Science, 7, 1555 (2014).

27. G. Patry, A. Romagny, S. Martinet, and D. Froelich, Energy Science \& Engineering, 3, 71 (2015).

28. P. A. Nelson, K. G. Gallagher, and I. Bloom, BatPaC (Battery Performance and Cost) Software, Argonne National Lab, http://www.cse.anl.gov/BatPaC/ (Accessed on August 11, 2017)

29. B. D. McCloskey, The Journal of Physical Chemistry Letters, 6, 4581 (2015).

30. Lithium-ion batteries: advances and applications, p. 664, Elsevier, Amsterdam (2014) 